\title{
Surveying effect kind of food on Biological parameters on Chrysoperla carnea (Neuroptera: Chrysopidae) under laboratory Conditions
}

\author{
Mahmoud Jokar ${ }^{1}$ and Mehdi Zarabi ${ }^{2}$ \\ 1- Department of Entomology and Plant Pathology, Abureihan Campous of \\ Agriculture, University of Tehran, IRAN. \\ 2- Assistant Professor of Department of Life Sciences Engineering, Faculty of New \\ Sciences and Technologies, University of Tehran, Tehran- IRAN. \\ Email: mjokar@ut.ac.ir
}

\section{ABSTRACT}

Chrysoperla carnea (steph.) is a major, cosmopolitan predator of some whitefly and Aphid. This research was evaluated relative consumption of three diets and effects of prey kinds on developmental times, mortality percentage of larvae and pupae, consumption rate, longevity, fecundity, fertility, and sex ratio on C.carnea. All larvae stages and adults were reared on the different diets: $3^{\text {rd }}$ nymphal stages Shizaphis graminum, and Bemisia tabaci (Biotype B), or a semi artificial diet (consist of honey, yeast, essential amino acid, and Distilled water) (10\%, 15\%, 25\%, 2.5\%, and $47.5 \%$ ). All experiments were conducted at $25 \pm 5^{\circ} \mathrm{C}, 60 \pm 5 \% \mathrm{RH}$, and photoperiod of 16:8 (L:D). Larval stages consumed 192.1 \pm 2.57 (no.) nymph Shizaphis graminum, and 479.7 \pm 4.08 nymph Bemisia tabaci in which results show significant difference between hosts consumed by larvae. There were significant differences between rate of oviposition, larvae longevity $12.29 \pm 0.81,14.02 \pm 0.9$ and $10.07 \pm 0.3$ day ,fertility ,and sex ratio on different diets (female: male when larvae fed on age of nymph Shizaphis graminum ,Bemisia tabaci and artificial diet was 53:47, 52:48 and 57:43). Considering above parameters, artificial diet can be a best choice for mass rearing $C$. carnea.

Key words: Chrysoperla carnea, Shizaphis graminum, Bemisia tabaci (Biotype B), Biological parameter, artificial diet

\section{INTRODUCTION}

Whitefly (Hem. Aleyrodidae) is tiny, sap-sucking insect that attacks wide range of hosts. Several species whiteflies are economically important. All species are phytophagous and some transmit viruses (Byrne, 1990). The most important whiteflies species in flower and vegetable greenhouses is Bemisia tabaci (Bellows et al, 1994). Many biological characteristics, including multivoltinism, broad host-range, ability to migrate, high reproductive rate, tolerance for high temperatures, ability to vector a variety of devastating plant viruses, and a propensity to develop resistance to a wide class of insecticides underlie its pest potential and have contributed to the difficulty of developing robust and sustainable management systems (Naranjo,2001). Schizaphis graminum (Rondani) are distributed throughout the world. Although they are not usually considered a major turf grass pest, they have been known to cause extensive damage to bluegrasses, fescues, and perennial ryegrasses. Greenbugs pierce the plants to feed on the juice and inject a toxin while feeding, which weakens the plant. Great infestations can result in chlorotic yellow and brown colored turf, which may then lead to large dead patches (Rick \& Villani, 1995). C.carnea, biological 
agents, controlled wide range of pest. C.carnea could manage Whiteflies and Wheat Aphid. C.carnea is benefit predator because compatibility with a variety of environmental conditions, food diversity and ability to hunt 80 species of pest. Greenlacewing is a voracious predator that larvae feed on all immature stages of Whiteflies and Wheat Aphid (Singh \& Varma, 1989). Releasing C.carnea in greenhouse has close relationship with cheap mass rearing. Adequate diet is cheap, available and nutritious (Tulisalo, 1984). Finney (1984) was the first that mass rearing C.carnea on larvae and egg potato tuber moth (Phthorimaea operculella). Now eggs of Grain moth (Tulisalo, 1984) and eggs of Mediterranean flour moth (Nicoli et al., 1991) were used in mass rearing. Other diets that were used in mass rearing are Myzus persicae (Tulisalo., and Korpela.1973), larvae Plodia interpunctella (Hassan,. 1989) and S.graminum (Barnes, 1975). Laboratory studies have shown that maize pollen can also serve as a food source for adult C. carnea (Sheldon and MacLeod, 1971). (Gharekhani, 2000) biological parameters of C.carnea that feed on three species aphids be reviewed and showed that the optimal diet is high weight pupae and low longevity. (Mannan et al., 1997) studied the biology of C. carnea on Aphis gossypii (Glover) and Myzus persicae (Sulzer). (Gautam \& Tesfaye, 2002) examined the effects of different combinations of 50\% honey solution, castor pollens and yeast on the longevity, fecundity, reproductive age and other reproductive attributes of the predatory insect, $C$. carnea. Ulhaq (2006) effect of different diets on the biology of adult C.carnea tested and showed high adult longevity, high oviparous, and low pupae and larvae period at artificial diet (honey, milk and yolk). Syed (2008) nine diets were offered to C.carnea larvae; out of those, six diets were comprised of minerals and vitamins and the remaining three were natural. Developmental time, mortality percentages, pupal weight and laid eggs were determined. Syed (2005) compared development times and predation of C.carnea on different densities of two hosts (bemisia tabaci, and amrasca devastans). Nawaz Khan (2005) tested development of C.carnea on eggs and etherized adults of sitotroga cerealella (oliv) and showed that although C. carnea can be successfully reared on both eggs and adults of S.cerealella, eggs proved to be comparatively better food for rearing C.carnea larvae. (Khuram \& Hafeez, 2008) Investigated effectiveness of C.carnea on the Population of Bemisia tabaci in different cotton genotypes and showed that use of $C$. carnea as bio-intensive IPM program reduced the insecticides and saved foreign exchange that spent on pesticide import. (Liu \& Chen, 2001) studied effects of three aphid species on development, survival and predation of C. carnea. (Yadav \& pathak, 2010) assessed effect of temperature on the consumption capacity of $C$. carnea reared on four aphid species. (Simmons \& Abd-Rabou, 2007) surveyed natural enemies of the sweet potato whitefly in ten vegetable crops in Egypt. (Burke \& Martin, 1956) different stage larval feeding rates on A.gossypii at $26^{\circ} \mathrm{C}$, as percent, was 14,23 , and 64 , respectively. (Zhang et al, 2010) examined suitability of Aphis craccivora (Koch) and B.tabaci (Gennadius) (biotype-B) eggs and nymphs as prey for pre-imaginal development and survival, adult longevity, and fecundity of the lacewing, Chrysopa pallens (Rambur) under laboratory conditions. Sattar (2010) invested on C.carnea as a biological control agent against cotton pests in Pakistan.

\section{MATERIALS AND METHODS}

\section{Predator culture}

Eggs of C.carnea were originally supplied from insectariums in University of Tehran and used to establish a laboratory colony. Larvae were fed egg of 
Mediterranean flour moth in petri separately. Adults were held in tube containers that were with moistened cotton pads and ventilated with fine polyester mesh. Adults lay on paper that covered inside surface of the tube.

The eggs were collected and, after hatching, larvae were reared on each diet separately. Test diets were $3^{\text {rd }}$ nymphal stages Shizaphis graminum, Bemisia tabaci, and an artificial diet (consist of honey, yeast, essential amino acid, and distilled water) (10\%, 15\%, 25\%, 2.5\%, and 47.5\%). The artificial diet was applied drop wise onto a piece of board $(1 \times 15 \mathrm{~cm})$ and was placed in dishes during the test. Newly emerged adults C.carnea were kept in the tubes described earlier.

\section{Predator feeding on $3^{\text {rd }}$ nymphal stages}

Infested leaves of tomatoes with B.tabaci and infested tiny leaves of wheat with S.graminum were placed in separate petri dishes $(7.5 \times 1.5 \mathrm{~cm})$. Then newly emerged larvae; they were released separately into dishes containing leaves infested by each prey species. Whiteflies and wheat aphid-infested leaves were replaced with fresh ones daily. Each dish was checked for the number of intact nymph every $24 \mathrm{~h}$ for 30 days. All experiments were conducted at $25 \pm 5^{\circ} \mathrm{C}, 60 \pm 5 \% \mathrm{RH}$ and photoperiod of 16:8 (L: D) h.

\section{Surveying parameters}

The consumption rate was studied only using whitefly and wheat common aphid as prey. Newly laid eggs of adults were removed from stock culture and transferred to petri dishes. Hatching time and fertility rate of eggs were determined by daily observations. Individual larvae was confined in petri dishes on pieces leaf disks infested with $3^{\text {rd }}$ nymphal stages of B.tabaci and S.graminum and semi artificial diet daily. Because of cannibalistic behavior of larvae on sibling larvae and eggs, the larval C.carnea was separated as soon as they became active. Newly enclosed adult females and males were also randomly transferred to petri dishes supplied whit fresh prey. The number of eggs laid, egg viability and adult mortality were recorded daily. Sex ratio was determined in 100 adults reared on each diet using morphological characters to identify the sexes.

\section{Statistical analyses}

One way ANOVA followed by Tukey's HSD post hoc test was used to compare biological traits (sex ratio, fecundity, fertility, longevity) on different diets. Differences were considered significant $(p<0.01)$. All analyses were conducted using statistical software (SAS 9.1).

\section{RESULTS}

Mean feeding of total larval period C.carnea was $192.1 \pm 2.57$ and $479.7 \pm 4.08$ on $3^{\text {rd }}$ nymphal stages of $S$. graminum and B.tabaci. There were significant differences in mean consumption of different prey type (Fig.1).

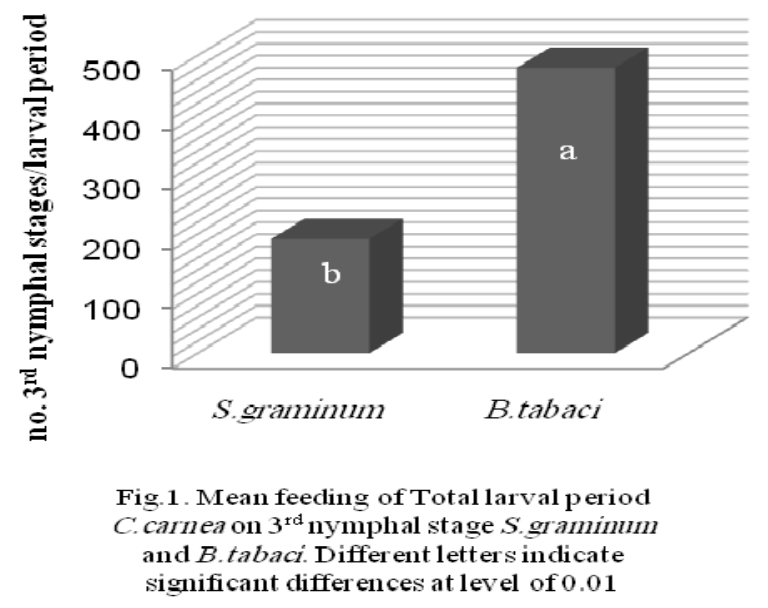


Mean feeding of different stages of larval C.carnea, respectively, was $21.8 \pm 0 / 69,42.5 \pm 0.72,127.8 \pm 1.16$ on $3^{\text {rd }}$ nymphal stages of $S$. graminum that were significant differences in mean consumption of different larvae stages. Mean feeding of different stages of larval C.carnea, respectively, was 48.15 $\pm 1.04,151.95 \pm 1.37$ and $279.9 \pm 1.67$ on $3^{\text {rd }}$ nymphal stages of B.tabaci that were significant differences in mean consumption of different larvae stages. Mean feeding of different stages of larval C.carnea on 3rd nymphal stages S.graminum and B.tabaci was significant. There were differences in mean consumption of different larvae stages (Fig.2). The weights of immature stages (larvae and pupae) green lacewings on whitefly, aphid, and artificial diet were $2.9 \pm 0.2,7.08 \pm 0.1 ; 3.34 \pm 0.14,8.4 \pm 0.18$; $3.68 \pm 0.15$, and $9.46 \pm 0.16$ (mgr), respectively, which showed significant differences on per diets. (Fig. 3).

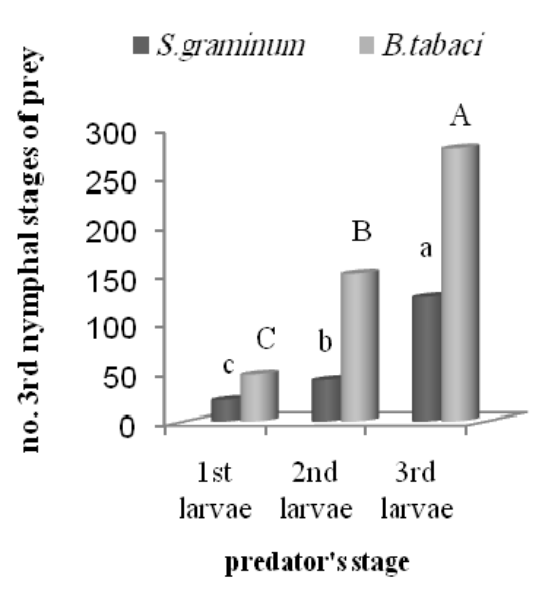

Fig. 2. Mean feeding of differ ent stages of larval C.carnea on $3^{\text {rd }}$ nymphal stage S.graminum and B. atabaci. Differ ent letters indicate significant differ ences at level of 0.01

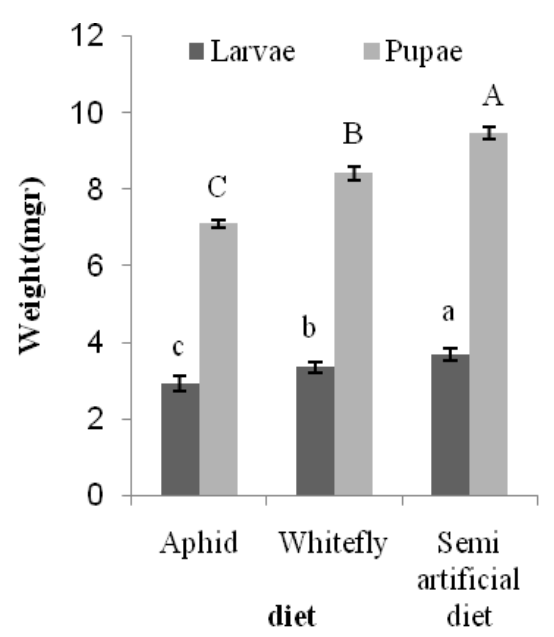

Fig. 3. mean weight of immature stages. Different letters indicate significant differences at level of 0.01

The Incubation period on deferent diets did not show significant differences. The entire larvae period took an average of $12.29 \pm 0.81,14.02 \pm 0.9$ and $10.07 \pm 0.3$ (day) for larvae predators which were reared on common wheat aphid, silver leaf whitefly and semi artificial diet, respectively. Also $1^{\text {st }}, 2^{\text {nd }}$, and $3^{\text {rd }}$ larval stages duration on aphid, whitefly, and semi artificial diet were significant differences. The least immature mortality percent than others diets belonged to semi artificial diet (Table 1). There was also a significant difference between rates of laid eggs on different diets (Table 2). Predators reared on semi artificial diet showed the highest ovipositor rates, but predators reared on silver leaf whitefly showed the lowest (15 eggs/female/day versus 10 eggs/female/day); fertility on S. graminum, B.tabaci, and semi artificial diets was $86 \%, 79 \%$, and $81 \%$, respectively. The sex ratio of C.carnea offspring reared on the three diets was significantly different (Table 2). Oviposition rates during 30 consecutive days showed regular flections on any diet (Fig.4). The highest oviposition rate range (7-15 eggs $\mathrm{d}^{-1)}$ occurred with artificial diet. 
Table 1: Duration of developmental immature stages C. carnea reared on two preys under lab con.

\begin{tabular}{|c|c|c|c|c|c|c|c|c|}
\hline $\begin{array}{l}\text { diets } \\
\end{array}$ & $\begin{array}{c}\text { Incubation } \\
\text { period(Day) } \\
\text { (Mean } \pm \\
\text { SD). } \\
\end{array}$ & $=-1 \mathrm{st}$ & Larvae Insta & s duration ( & Total & $\begin{array}{c}\text { Pupal } \\
\text { stage } \\
\text { (Day). }\end{array}$ & $\begin{array}{c}\text { Larvae } \\
\text { Mortality } \\
\%\end{array}$ & $\begin{array}{c}\text { Pupal } \\
\text { Mortality } \\
\%\end{array}$ \\
\hline S.graminum & $3.8 \pm 0.31^{\mathrm{ns}}$ & $3.8 \pm 0.24^{\mathrm{a}}$ & $3.94 \pm 0.19^{b}$ & $4.43 \pm 0.13^{b}$ & $12.29 \pm 0.81^{b}$ & $8.14 \pm 0.14^{b}$ & 6 & 8 \\
\hline $\begin{array}{c}\text { B.tabaci } \\
\text { (biotype B). }\end{array}$ & $4.04 \pm 0.22^{\mathrm{ns}}$ & $4.22 \pm 0.3^{\mathrm{a}}$ & $4.5 \pm 0.16^{\mathrm{a}}$ & $5.3 \pm 0.35^{\mathrm{a}}$ & $14.02 \pm 0.9^{\mathrm{a}}$ & $8.9 \pm 0.32^{\mathrm{a}}$ & 18 & 12 \\
\hline $\begin{array}{c}\text { Artificial } \\
\text { diet }\end{array}$ & $3.7 \pm 0.45^{\mathrm{ns}}$ & $3.09 \pm 0.18^{b}$ & $3.3 \pm 0.3^{\mathrm{c}}$ & $3.67 \pm 0.3^{\mathrm{c}}$ & $10.07 \pm 0.3^{c}$ & $7.15 \pm 0.34^{\mathrm{c}}$ & 4 & 0 \\
\hline
\end{tabular}

Table 2: Comparing sex ratio, fecundity, fertility and larval longevity of $C$. carnea on different diets.

\begin{tabular}{cccc}
\hline Diets & $\begin{array}{c}\text { Sex ratio } \\
\text { (F:M). }\end{array}$ & $\begin{array}{c}\text { Fecundity } \\
\text { (egg/female/day) } \pm \text { SE }\end{array}$ & $\begin{array}{c}\text { Fertility } \\
\text { (fertile egg/day)(\%). }\end{array}$ \\
\hline S. graminum & $1.14^{\mathrm{a}}$ & $11.17 \pm 0.31^{\mathrm{b}}$ & 0.86 \\
B.tabaci & $1.09^{\mathrm{a}}$ & $10.15 \pm 0.24^{\mathrm{b}}$ & 0.79 \\
Artificial diet & $0.92^{\mathrm{b}}$ & $15.67 \pm 0.32^{\mathrm{a}}$ & 0.81 \\
\hline
\end{tabular}

Different letters indicate values are significantly different (ANOVA.Tukey’s HSD post hoc test, $p=0.01$ ).

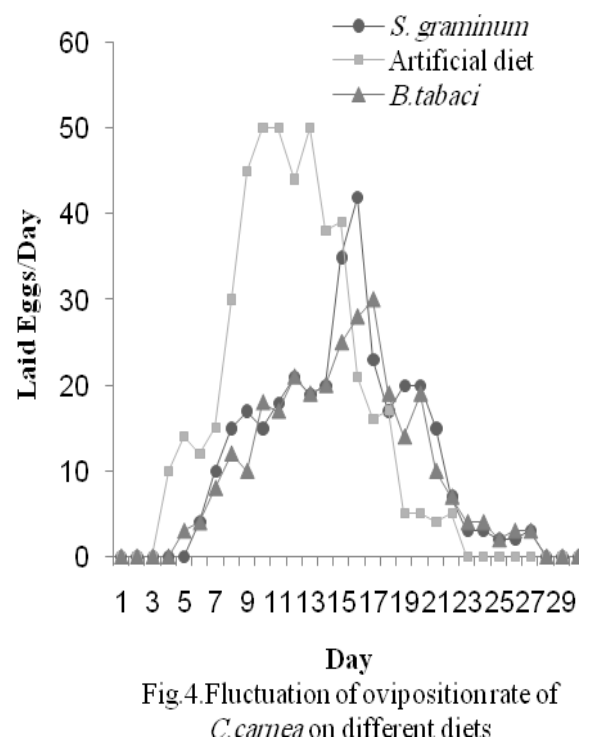

\section{DISCUSSION}

This study larvae and pupae duration on semi artificial diet $(12.29 \pm 0.81,8.14 \pm 0.14)$ was of similar result to (Ulhaq et al., 2006). Our results show that feeding is influenced by increasing age of larvae, increasing feeding rate, which agrees with the results of Burke and Martin (1954), and Chakraborty (2009) who studied number of six species aphids consumed during larval stages C. carnea which showed increasing trend of the larval feeding. Chen and Liu (2001) prey consumption's $C$. rulabris on Aphis gossypii (141.6 \pm 2.2 aphids/larva) and Myzus persicase(168.0 \pm 2.8 aphids/larva), was similar to our observation, and in Sattar (2010). The total food consumption of a single larva of $C$. carnea was 509.5 the number of A. gossypii was different form our results. Syed (2005) compared mean number of $3^{\text {rd }}$ nymphal stage of b.tabaci 
(200 no nymph/larvae), different from our result. It was $479.7 \pm 4.08$. This current result is compared with relative consumption and flections immature weights which proved immature stages of green lacewings have higher consumption rate on whitefly between live diet. It has higher weight on aphid (Fig.5). These results of immature weight on three diets were similar to results gained by Sattar (2010).

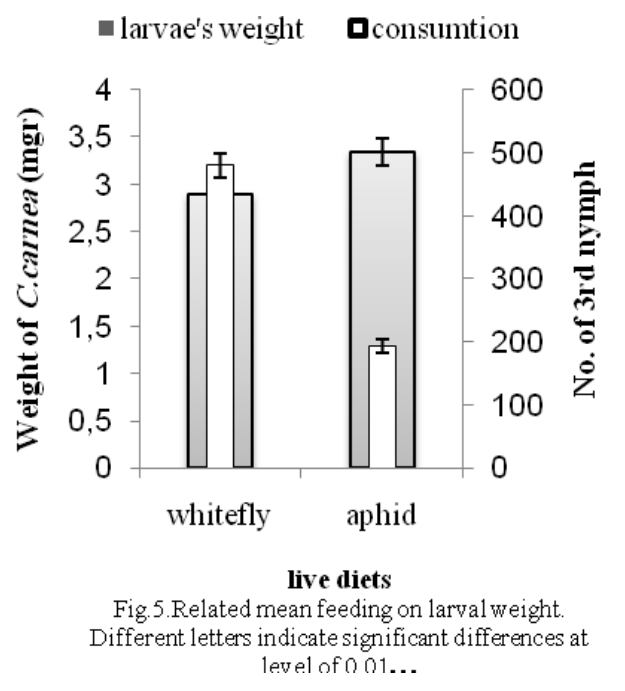

Syed (2005) compared different instars larvae duration of C.carnea on two hosts (Bemisia tabaci, and Amrasca devastans), that is very similar to our experiments; results show that whitefly was shorter cycle, 10.25 days. Our result was $14.02 \pm 0.51$ day that this visible difference may be caused by different photoperiod. Mannan et al. (1997) the durations of development of 1st, 2ed and 3rd larvae were 2.60, 2.25, 2.38 and 3.75, 2.78 and 3.35 days when reared on A. gossypii and M. persicae, respectively, like our result. (Sheldon \& MacLeod 1971) reported that mean egg during fertilization laid 12.2 and 12.4(egg/longevity) on sugar, yeast, pollen and only yeast. Also the results of the present study showed that fecundity reared on different diets is significantly different. Mannan et al. (1997) observed mean fecundity of C. carnea about 84.70 and 103 eggs on Aphis gossypii and Myzus persicae lesser than our current fecundity. The fecundity result on artificial diet $(15.56 \pm 0.32)$ was similar to Tesfaye et al. (2002) that the oviposition ranged from 6.14 to 27.11 eggs/ day. Fertility rate belonged to feeding aphid diet (86 \%) more than feeding whitefly diet (81\%), our result was similar one's Zhang et al., (2010) for Chrysopa pallens. According to our results the highest oviposition rate and the lowest mean larval duration occurred when C.carnea was fed on artificial diet in contrast, predators that fed on pest and laid more eggs but had the shortest lifespan. Certainly, the sexual and egg laying behaviors need more energy. Thus, laying more eggs may result in a shorter life cycle.

\section{REFERENCE}

Anila N. S., M. Ashfaq and S. Ahmad. (2008). Comparative Effect of Various Diets on Development of Chrysoperla carnea ( Neuroptera. Chrysopidae ). International Journal of Agriculture and Biology, 728-730. 
Barnes, B. N. The life history of Chrysopa zastrowi Esb-Pet. (Neuroptera: Chrysopidae) (1975). Journal of Entomological Society of Southern Africa., 38:47- 53.

Burke, H. R. and Martin, D. F. (1956). The biology of three chrysopid predators of the cotton aphid, J. Econ. Entomol., 49: 698-700.

Byrne, D. N., and W. B. Miller. (1990). Carbohydrate and amino acid composition of phloem sap and honeydew produced by Bemisia tabaci. J. Insect Physiol. 36: 433-439.

Chakraborty. D. and D. M. Korat. (2010). Biology of green lacewing , Chrysoperla carnea (Stephens ) in middle Gujarat conditions. Karnataka J. Agric. Sci. 23: 500-502.

Finney, G. L. (1948). Culturing Chrysopa californica and obtaining eggs for field distribution. Journal of Economic Entomology, 41: 719-721.

Gautam, R. D. and Tesfaye, A. (2002). Potential of green lacewing, Chrysoperla carnea (Stephens) in crop pest management. New Agric., 13: 147-58.

Gharakhany, G. H., Talebi C., P. M. Milany, and Hejazi, M. J. (2000). A Study on the effect of several prey consumption on developmental stages, duration and pupal weight increases in Chrysoperla carnea (Steph.). Proceeding of the $14^{\text {th }}$ Iranian Plant Protection Congress, 171p.

Hassan, S.A. (1989). Rearing of Trichogramma cacoecia March. P 291-298. In: SamsoePetersen, L. et al. (eds.), Laboratory rearing techiniques for 16 beneficial arthropod species and their prey. Z. Pflkrankh. Pflschutz. 96 (3): 289-316.

Nawaz Khan, M. I., Naeem, M., Salihah, Z., Sattar, A., and Farid, A. (2005). Development of Chrysoperla carnea (STEPH.). On eggs and etherized adults of Sitotroga cerealella (oliv). Sarhad Journal Agricult., 21.

Iqbal, M., Khan, N., Naeem, M., Salihah, Z., Sattar, A. and Farid, A. (2005). Development of Chrysoperla carnea Steph. On eggs and etherizes adults of Sitotroga cerealella Oliv. Sarhad J. Agric, 21.

Khuram, Z., Faisal, H., Rashid, R. KHAN. (2008). Effectiveness of Chrysoperla carnea (Stephens) (Neuroptera: Chrysopidae) on the Population of Bemisia tabaci (Homoptera: Aleyrodidae) in different cotton genotypes. J. Agri. Social Scie, 112-116.

Liu, T. X., and Chen, T. Y. (2001). Effects of three aphid species (Homoptera: Aphididae) on development, survival and predation of Chrysoperla carnea (Neuroptera: Chrysopidae). Ap. Entomol. Zool, 36(3): 361-366. doi:10.1303/aez. 2001.361

Mannan, V. D., Varma, G. C and K. S. Brav. (1997). Biology of Chrysoperla carnea Stephens on Aphis gossypii (Glover) and Myzus persicae (Sulzer). J. Insect Sci., 10: 43-145.

Muzammil, S. (2010). Investigations on Chrysoperla carnea (Stephens) (Neuroptera: Chrysopidae) as a biological control agent against cotton pests in Pakistan. Sindh agriculture university, Tandojam.

Naranjo, S.E. (2001). Conservation and evaluation of natural enemies in IPM systems for Bemisia tabaci. Crop Protection, 20:835-852.

Nicoli, G., Galazzi, D., Mosti, M., and Burgio, G. (1991). Embryonic and larval development of Chrysoperla carnea at different temperature regimes. Bulletine, SROP, 14(5): 43-49.

Rick L. B. and Michael G. V. (1995). Handbook of Turfgrass Insect Pests (p. 140). Entomological Society of America.

Sheldon, J. K. and MacLeod, E. G. (1971). Studies on the biology of the Chrysopidae 11. The feeding behavior of the adult of Chrysopa carnea (Neuroptera). Psyche, Camb. 78: 107-121. 
Shi, Z. Z., Rui, X. J., Fan, Z. X. L. X. and Tong, X. L. (2010). Suitability of Aphis craccivora (Hemiptera: Aphididae) and Bemisia tabaci (Hemiptera: Aleyrodidae) biotype-B as prey for Chrysopa pallens (Neuroptera: Chrysopidae). Bio. Science and Tech., 20(9): 961-971.

Simmons, A. M. and Abd-Rabou, S. (2007). Survey of Natural Enemies of the Sweet potato Whitefly (Hemiptera: Aleyrodidae) in Ten Vegetable Crops in Egypt. J. Agri. Urban Entomol, 24(3):137-145. doi:10.3954/1523-5475-24.3.137.

Singh, P. P. and Varma, G. C. (1986). Comparative toxicities of some insecticides to Chrysoperla carnea (Chrysopidae: Neuroptera) and Trichogramma brasiliensis (Trichogrammatidae: Hymenoptera), two arthropod natural enemies of cotton pests. Agric. Ecosystems Environ., 15: 23-30.

Syed, A. N., Ashfaq, M., and Khan, S. (2005). Comparison of development and predation of Chrysoperla carnea (Neuroptera: Chrysopidae) on different densities of two hosts (Bemisia tabasci and Amrasca devastants) Pak. Entomol., 27(1): 41-44.

Syed, N. A., M. Ashfaq and S. Ahmad. (2008). Comparative Effect of Various Diets on Development of Chrysoperla carnea (Neuroptera,:Chrysopidae ). International journal of agriculture \& biology., pp.728-730.

Tulisalo, U. (1984). Mass rearing techniques. pp. 213- 220. In Canard, M., Semeria, Y. and New, T.R. (eds.), Biology of Chrysopidae. Junk, Boston.

Tulisalo, U. and S. Korpela. (1973). Mass rearing of the green lacewing (Chrsoperla carnea Steph.). Annales Entomologici Fennici. 39 (3):143-144.

Ulhaq, M. M., Sattar, A., Salihah, Z., Farid, A., Usman, A., Ullah, S. and Khattak, K. (2005). Effect of different artificial diets on the biology of adult green lacewing (Chrysoperla carnea Stephens.) Effect of different artificial diets on the biology of adult green lacewing. Songklanakarin J. Sci. Technol., (April 2005), 1-8.

Yadav, R. and Pathak, P. H. (2010). Effect of temperature on the consumption capacity of Chrysoperla carnea (Stephens) (Neuroptera: Chrysopidae) reared on four aphid species. Development, 5(2): 271-274. 